\title{
PRODUÇÃO E AVALIAÇÃO NUTRICIONAL DE FARINHA DE MOYASHI - BROTO DE FEIJÃO MUNGO-VERDE (Vigna radiata, Fabaceae).
}

\section{PRODUCTION AND NUTRITIONAL EVALUATION OF MOYASHI FLOUR - MUNGO- VERDE BEANS BRITA (Vigna radiata, Fabaceae).}

\author{
SILVA, J. M. H. M. ${ }^{1}$; MAIA, M. E. P. ${ }^{1}$; BERGMANN, M. F. ${ }^{1}$; BRUSKE, M. ${ }^{1}$; ROCHA, M. \\ C. ${ }^{1}$; GIOVANETTI, R. X. ${ }^{1}$; CARVALHO, T. P. ${ }^{1}$; BALBI, M. E. ${ }^{2}$
}

1 - Graduandas em Farmácia, Universidade Federal do Paraná (UFPR).

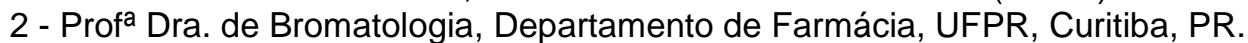

Autor para correspondência: bromatologia.ufpr@gmail.com

\section{RESUMO:}

A Vigna radiata (L.) Wilczek popularmente conhecida como mungo-verde ou feijão-moyashi é um membro da família das leguminosas Fabaceae. Esta leguminosa é de fácil adaptação nos climas tropicais e subtropicais, sendo utilizada principalmente como suplemento proteico em diferentes pratos utilizando a farinha ou a leguminosa bruta, devido suas fontes de minerais, vitaminas, proteínas e baixas calorias o que o tornou popular no Brasil pela procura de alimentação saudável. Neste sentido, o objetivo do trabalho foi realizar uma avaliação química e nutricional do broto de feijão-moyashi e da farinha produzida a partir dele. Para isso o alimento adquirido da Chácara Paraíso, passou inicialmente por uma análise macroscópica e foi submetido a várias determinações como: umidade, proteínas, lipídios, fibras e minerais, obtendo os seguintes resultados: $94,89 \%, 1,31 \%, 0,038 \%, 1,46 \%$ e $0,266 \%$, respectivamente para o broto de feijão e $16,10 \%, 25,82 \%, 0,74 \%, 28,51 \%$ e $5,20 \%$, para a farinha. Os dados de carboidratos foram obtido por diferença, 2,03\% para o broto de feijão e $23,63 \%$ para a farinha. A partir dos dados obtidos comparou-se os resultados com os estabelecidos pela tabela TACO, e ainda com outras farinhas comerciais. Os valores nutricionais encontrados para o broto de feijão se mostraram próximos aos valores estabelecidos. Já a farinha do broto de feijão-moyashi se destacou pela grande quantidade de proteínas, baixo teor lipídico e grande quantidade de fibras, sendo assim, uma opção saudável para indivíduos veganos e vegetarianos por ser muito nutritiva e economicamente acessível.

Palavras-chave: broto de feijão, moyashi, farinha, Vigna radiata.

\section{ABSTRACT:}

The Vigna radiata (L.) Wilczek, popularly known as mung bean or moyashi bean is a member of the Fabaceae leguminous family. This legume is easily adapted to tropical and subtropical climates, being used mostly as a protein supplement in different recipes, by using its flour or the leguminous itself, due to its mineral, vitamin, and protein contents and even more for the sprout's low calorie feature, which turned the beans sprouts popular in Brazil due to a search for a healthier lifestyle. In this scope, it is intended to realize a chemical and nutritional evaluation of the mung bean's sprouts and it's farina. For that, the leguminous obtained from Chácara Paraíso was submited to a macroscopic analysis and then to a diverse gama of determination tests, such as moisture, protein, lipid, fibers and mineral contents, which gave the following results: 94,89\%, 1,31\%, 0,038\%, 1,46\% e $0,266 \%$ respectively for the sprouts and $16,10 \%, 25,82 \%, 0,74 \%, 28,51 \%$ e $5,20 \%$ for the 
farina. Carbohydrate data were calculated by subtraction, $2,03 \%$ for the sprout and $23,63 \%$ for the farina. The results obtained were compared to the TACO index and to other comercial farinas. Sprouts nutritional values were close to the established ones. The farina results, on the other hand, stood out on it's low lipidic and high protein and fiber content. Therefore, the farina appears as an interesting and healthy supplement option for vegan and vegetarian individuals, for it's nutritional value and easy economic access.

Key-words: bean sprouts, mung bean, moyashi, flour, Vigna radiata.

\section{INTRODUÇÃO}

A Vigna radiata (L.) Wilczek popularmente conhecida como mungo-verde ou feijãomoyashi é um membro da família das leguminosas Fabaceae. A família Fabaceae é conhecida pela sua ampla variedade de gêneros e espécies, sendo considerada a terceira maior família de plantas (ISMAIEL, 2004).

O mungo-verde tem fácil adaptação nos climas tropicais e subtropicais, sendo cultivado em diferentes regiões da Ásia. A Índia é o maior produtor mundial dessa leguminosa, chegando a $47 \%$ do total produzido no mundo. A principal utilização do mungoverde é como suplemento proteico em diferentes pratos utilizando a farinha ou a leguminosa bruta, em substituição à carne. No Brasil a produção é voltada principalmente para obtenção do broto de feijão (VIEIRA 2001).

Durante o desenvolvimento vegetal a fase mais rica em nutrientes é a germinação, já que, as leguminosas ao germinar multiplicam seus nutrientes tendo os maiores níveis de proteína, carboidratos e lipídeos (LOURES, 2007).

As sementes germinadas (dois a três dias) dão origem ao caule e as folhas, que vão preenchendo-se com clorofila, originando os brotos (cinco a sete dias). Os brotos são considerados alimentos totalmente naturais, já que não necessitam a utilização de adubos e defensivos agrícolas durante o seu crescimento (LOURES, 2007; OLIVEIRA, et al, 2013).

A Vigna radiata é a espécie mais utilizada para produção de brotos no Brasil. No mundo os brotos de feijão (Moyashi), são muito consumidos pela China, Japão e EUA, sendo estes, os maiores importadores da espécie (LOURES, 2009).

O broto de feijão comestível, ou moyashi, é uma leguminosa obtida através da germinação de sementes de feijão em ambientes escurecidos. Ao contrário dos brotos de feijão destinados ao cultivo da planta que germinam na presença de luz e assim em poucos dias apresentam uma coloração verde, no moyashi apresenta-se uma cor esbranquiçada, pois os cloroplastos não se desenvolveram devido à ausência de iluminação (SCHARDONG, et al., 2013). 
Os brotos são altamente nutritivos devido suas fontes de minerais, vitaminas, proteínas e baixas calorias o que o tornou popular no Brasil pela procura de alimentação saudável. Segundo Vieira (2001), o teor de proteínas dos grãos desta leguminosa pode variar de $19,5 \%$ a $31,2 \%$, o grão ainda possui $10,6 \%$ de água, $4,4 \%$ de fibras, $1,2 \%$ de lipídios e 3,5\% de cinzas ricos em $\mathrm{Ca}, \mathrm{P}, \mathrm{Fe}, \mathrm{Na}$ e K. Mais especificamente sobre o broto de feijão, Fordham e colaboradores (1975) descreve que o mesmo possui $86 \%$ a $91 \%$ de água, $2,7 \%$ a $4,3 \%$ de proteínas, 0,4 a $0,8 \%$ de cinzas, $0,6 \%$ de fibras e $0,1 \%$ a $0,2 \%$ de lipídeos.

A secagem do broto e posterior produção da farinha do Moyashi garante algumas vantagens em relação ao produto in natura. A farinha pode ser uma substituinte de outros ingredientes em receitas capazes de serem adaptadas para o consumo, de acordo com a necessidade do consumidor, por exemplo em pães ou massas de pizza. Além disso, a farinha é uma opção mais fácil de ser introduzida nas dietas, incluindo infantis, as quais necessitem dos nutrientes e compostos contidos no broto de feijão (CROCETTI, et. al., 2016). Ademais, a secagem do broto de feijão diminui a atividade da água, aumentando o tempo de prateleira do produto. Tal fato se deve pela diminuição da carga microbiana presente, sendo assim, a farinha garante maior tempo de validade para consumo (MOURA, et. al., 2007).

O objetivo deste artigo é realizar uma avaliação nutricional broto de feijão através de técnicas já descritas na literatura e assim, conseguir produzir uma farinha rica em proteínas e com baixo teor lipídico, que poderá ser utilizada em receitas, substituindo farinhas normais como por exemplo a de trigo, trazendo mais benefícios à saúde do consumidor.

\section{MATERIAL E MÉTODOS}

\subsection{MATERIAL}

Para realização das análises foi utilizado o broto de feijão in natura comprado no mercado municipal de Curitiba. O material foi colhido nas mesmas condições na chácara paraíso, localizada no município Fazenda Rio Grande - PR. O material estava em sacos plásticos de $500 \mathrm{~g}$ cada um, totalizando $2,0 \mathrm{Kg}$ de amostra.

As análises foram todas realizadas no Laboratório de Bromatologia do Departamento de Ciências Farmacêuticas da Universidade Federal do Paraná (UFPR), Campus Jardim 
Botânico em Curitiba. A produção da farinha foi realizada no mesmo local, e foi feita a moagem em um gral de porcelana com pistilo.

\subsection{METODOLOGIA}

\subsubsection{Análise macroscópica}

As análises macroscópicas foram feitas a fim de analisar características dos brotos de feijão como cor, odor, sabor e aparência. O moyashi é um broto que apresenta cotilédones com cor verde e hipocótilo na cor branca, seu odor é semelhante à de vegetação e o sabor similar ao da alface (VIEIRA, 2001).

\subsubsection{Análises químicas e nutricionais}

As análises da composição química e nutricional seguiram as seguintes metodologias:

- Determinação de umidade - Técnica voláteis a $105^{\circ} \mathrm{C}$ descrito em IAL, 2008.

- Determinação de nitrogênio total - Micro Kjeldahl descrito em A.O.A.C, 1995. Foi utilizadoo fator de conversão para proteínas 5,75 segundo recomendações da RDC 360 (BRASIL, 2003).

- Determinação de lipídeos - Extrato etéreo descrito em IAL, 2008.

- Determinação de fibras descrito em A.O.A.C, 1970.

- Determinação de minerais - Resíduo mineral fixo descrito em IAL, 2008.

- Determinação de carboidratos - Realizado por método indireto (diferença).

- Estudo estatístico (média e desvio padrão).

\section{RESULTADOS E DISCUSSÃO}

\subsection{Análise sensorial}

$\mathrm{Na}$ análise sensorial os brotos de feijão mungo apresentaram cor: normal, branco amarelado; odor: característico, semelhante à vegetação; observou-se presença de cortes mecânicos e alguns deles não apresentavam cotilédones. 


\subsection{Análises da Composição Química e Nutricional}

Os valores obtidos da composição química nutricional podem ser observados na Tabela 1.

De acordo com Vieira (2001), os grãos de Vigna radiata possuem cerca de 10,6\% de água, porém, os resultados obtidos mostram uma porcentagem de umidade de 94,89\%, esta grande variação pode ser explicada já que no processo de germinação ocorre hidratação das sementes a fim de promover o crescimento da planta.

Ainda sobre o parâmetro de umidade, o valor obtido de $94,89 \%$ pode ser comparado aos valores dos estudos de Fordham e colaboradores (1975) e os valores de referência da tabela TACO (2011) que determinam a umidade do broto de feijão (moyashi) de $86-91 \%$ e $87,5 \%$ respectivamente. Apesar do valor obtido ser superior aos de referência, o mesmo se encontra próximo do esperado.

É possível verificar uma grande vantagem na produção da farinha do broto de feijão a partir do parâmetro de umidade. Este processamento do broto de feijão pode conferir maior tempo de prateleira a este tipo de alimento já que a umidade do alimento cai para $16,10 \%$, diminuindo a deterioração microbiológica.

\section{TABELA 1 - RESULTADOS OBTIDOS DA COMPOSIÇÃO QUÍMICA E NUTRICIONAL EM 100g DE BROTO DE FEIJÃO (Vigna Radiata) E SUA FARINHA.}

\begin{tabular}{lcc}
\hline Determinação & Broto de feijão (moyashi) & Farinha \\
\hline Umidade & $94,89 \% \pm 0,36 \%$ & $16,10 \% \pm 0,65 \%$ \\
Proteínas* $^{*}$ & $1,31 \% \pm 0,006 \%$ & $25,82 \% \pm 0,12 \%$ \\
Lipídeos & $0,038 \% \pm 0,002 \%$ & $0,74 \% \pm 0,04 \%$ \\
Carboidratos ${ }^{\star *}$ & $2,03 \%$ & $23,63 \%$ \\
Fibras & $1,46 \pm 0,09 \%$ & $28,51 \% \pm 1,84 \%$ \\
Minerais & $0,266 \% \pm 0,004 \%$ & $5,20 \% \pm 0,08 \%$ \\
Kcal total & 13,75 Kcal & $204,46 \mathrm{Kcal}$
\end{tabular}

NOTA: *Utilizou-se o fator de conversão de proteínas 5,75 para o broto de feijão e farinha (Brasil, 2003). ${ }^{* *}$ Obtido por diferença. 
A utilização de broto de feijão ocorre principalmente, pelo valor proteico nele incluso, sendo considerado a $8^{\mathbf{a}}$ hortaliça com maior teor de proteínas (TACO, 2011). Podemos comparar os valores proteicos obtido da farinha de broto de feijão 25,82\%, com outros estudos utilizando brotos de outras espécies.

Barcelos e colaboradores (2002) estudaram a composição nutricional do broto de milho seco, concluindo que a matéria seca do produto tinha 9,84\% de proteínas. Já Oliveira, et al. (2013) estudou a composição nutricional da farinha de beterraba em comparação a farinha de trigo, declarando que quantidade de proteína chegava a 13,64\% e 9,8\% respectivamente.

Desta maneira, a utilização da farinha de broto de feijão pode ser utilizada como substituinte de farinhas normalmente utilizadas em receitas, como a farinha de trigo, por apresentar um maior valor protéico podendo complementar a dieta de vegetarianos e veganos e favorecer o ganho de massa muscular.

Além de um valor proteico considerável, a baixa carga lipídica do broto de feijão o tornou um atrativo ainda maior para indivíduos que almejam uma alimentação saudável. As análises químicas do broto de feijão resultaram em porcentagens lipídicas inferiores a 0,1\%, valor estabelecido pela TACO (2011) para este alimento. Em relação a farinha, pode-se observar porcentagens de lipídios consideravelmente inferiores aos estabelecidos por Oliveira, et al. (2013) em seu estudo. Ademais, as porções foram equivalentes à uma baixa porcentagem dos valores diários recomendados pela RDC 360 (BRASIL,2003), ao observar a tabela 2.

TABELA 2 - INFORMAÇÃO NUTRICIONAL DE BROTO DE FEIJÃO (Vigna radiata) NA PORÇÃO CASEIRA UMA COLHER E MEIA DE SERVIR (81g) E DA SUA FARINHA NA PORÇÃO CASEIRA DE 3/4 DE XÍCARA (65g).

\begin{tabular}{|c|c|c|c|c|}
\hline Informação & $\begin{array}{c}\text { g/ } 81 \mathrm{~g} \text { de broto de } \\
\text { feijão }\end{array}$ & VD\%* & $\mathrm{g} / 65 \mathrm{~g}$ de farinha & VD\%* \\
\hline Valor Energético & 11,14 Kcal & $0,56 \%$ & $132,90 \mathrm{Kcal}$ & $6,65 \%$ \\
\hline Carboidrato & $1,65 \mathrm{~g}$ & $0,33 \%$ & $15,36 \mathrm{~g}$ & $3,07 \%$ \\
\hline Proteína & $1,06 \mathrm{~g}$ & $0,21 \%$ & $16,78 \mathrm{~g}$ & $3,36 \%$ \\
\hline Gordura total & $0,03 \mathbf{g}$ & $0,01 \%$ & $0,48 \mathrm{~g}$ & $0,22 \%$ \\
\hline Fibras & $1,18 \mathrm{~g}$ & $4,72 \%$ & $18,53 \mathrm{~g}$ & $74,13 \%$ \\
\hline
\end{tabular}

*Segundo a RDC 360 (BRASIL, 2003). 
Segundo Bernaud e Rodrigues (2013) o consumo de fibras gera efeitos positivos ao organismo, influenciando na velocidade do trânsito intestinal, $\mathrm{pH}$ do cólon e produção de subprodutos com importante função fisiológica. A partir de estudos desenvolvidos nos últimos anos observou-se que indivíduos com alto consumo de fibras apresentam menores riscos de desenvolvimento de doença coronariana, hipertensão e obesidade, já que as fibras contribuem com a diminuição dos níveis séricos de colesterol. O consumo ainda traz menores riscos de câncer de cólon e desenvolvimento de diabetes.

O broto de feijão se mostrou com um teor de fibras insignificante, assim não é adequado para ser um produto usado como fonte alternativa desse elemento. Pelo contrário, a farinha do broto de feijão teve um teor de fibras muito alto, sendo possível utilizá-lo como um alimento fonte de fibras ou para suplementação do nutriente. De acordo com Dreher (1995) um alimento com teor de 2 a 3\% de fibras alimentares pode ser considerado uma boa fonte de fibras, o que não é apresentado pelo broto, mas pela farinha temos um teor de $28,51 \%$, sendo um alimento com boa fonte de fibras.

Segundo Malucelli e colaboradores (2009), que realizaram as análises físicoquímicas do talo de brócolis e da farinha de resíduo de brócolis, o teor de fibra obtido foi respectivamente $2,9 \%$ e $18,4 \%$. Portanto comparando o produto in natura e a farinha do broto de feijão com o talo de brócolis e a farinha, o produto in natura que foi analisado com esse estudo não é indicado para elevar ou suprir o consumo de fibras de quem pretende utilizá-lo para este fim, mas a farinha atende esses requisitos, sendo mais eficiente para isso do que a farinha de resíduo de brócolis, por exemplo.

Os minerais participam de funções básicas do organismo humano, como regulação da pressão arterial e formação de tecidos. A Organização Mundial de Saúde (OMS) descreve 18 minerais, como zinco, cálcio, ferro, magnésio, iodo, selênio e outros, como fundamentais para o bom funcionamento do organismo. O teor de minerais do broto de feijão analisado de acordo com IAL (2008) apresentou uma quantidade muito baixa de minerais. Desta maneira não é recomendado usá-lo como fonte de minerais ou de suplementação.

Já a farinha de broto de feijão apresentou uma quantidade de minerais de 5,20\%. O cálcio é um dos minerais mais reconhecidos pela sua importância na liberação de neurotransmissores, bom funcionamento do coração, ossos e dentes. A necessidade diária desse mineral para adultos é estabelecida em 1000 mg por dia segundo Pereira e colaboradores (2009), e seria facilmente comprida pela quantidade de minerais verificada na farinha, entretanto não é possível afirmar os valores exatos de cada mineral já que a 
análise realizada verificou apenas o valor de minerais totais na amostra.

Pela importância de cada mineral no metabolismo do corpo humano seria interessante em estudos futuros realizar a determinação de cada mineral individualmente na amostra de farinha de broto de feijão, já que foi obtido um valor maior de $5 \%$ de minerais nesta amostra.

Em relação aos carboidratos, foram encontrados os valores de 2,03\% para o broto de feijão (Vigna radiata) e $23,63 \%$ para a farinha, em $100 \mathrm{~g}$ dos produtos. Isso certifica o número estabelecido pela TACO (2011), sendo esse 7,8 $\mathrm{g}$ de carboidrato em $100 \mathrm{~g}$ de broto de feijão cru, ou seja, $7,8 \%$, valor considerado baixo assim como o calculado pelo método de diferença em nossos experimentos. Já a farinha do broto de feijão, quando comparado a uma farinha comumente usada, como a de trigo, que possui $75,1 \mathrm{~g}$ de carboidratos em $100 \mathrm{~g}$ (TACO, 2011), apresentou teor de carboidratos consideravelmente menor, de 23,63\%, como já exposto anteriormente. Visto isso, a farinha do broto de feijão é uma melhor alternativa para pessoas que buscam uma alimentação saudável, e que pode desempenhar um objetivo semelhante em uma receita.

Posteriormente à avaliação dos resultados da composição química e nutricional, foi possível calcular os valores diários de referência e valor energético conforme a RDC №360 (Brasil, 2003). Para a determinação desses foram utilizados $81 \mathrm{~g}$ do broto de feijão (Vigna radiata) e $65 \mathrm{~g}$ da sua farinha, sendo esses valores as respectivas porções caseiras referentes aos produtos analisados.

\section{CONCLUSÕES}

A farinha do broto de feijão-moyashi mostrou-se como viável suplemento proteico, em especial para indivíduos veganos e vegetarianos que carecem em fontes de proteínas em suas dietas. Ademais, pode ser uma alternativa para celíacos ao substituir a farinha de trigo na alimentação. Nesse viés, outra vantagem que pode ser destacada é o baixo teor lipídico e grande quantidade de fibra, sendo assim uma opção saudável e interessante.

Por fim, o broto de feijão (Vigna radiata) é também economicamente acessível, orgânico e de crescimento rápido. E pode ainda ser produzido em climas variados, adequando-se ao plantio em todo o território brasileiro. 


\section{REFERÊNCIAS}

AOAC - Association of Official Analytical Chemists. Official methods of analysis of the Association of the Analytical Chemists. 16th ed. Washington, 1995.

BARCELOS, M. de F. P.; BOAS; E. V. de B. V. LIMA, M. A. C. Aspectos nutricionais de brotos de soja e de milho combinados. Ciênc. agrotec., Lavras, v.26, n.4, p.817-825, jul./ago., 2002

BERNAUD, F. S. R.; RODRIGUES, T. C. Fibra alimentar - Ingestão adequada e efeitos sobre a saúde do metabolismo. Arquivos Brasileiros de Endocrinologia \& Metabologia. Porto Alegre, v.57, n.6, p.397-405. 2013.

BRASIL. Resolução ANVISA RDC n 360, de 23 de dezembro de 2003. Decreto n. 3029, de 16 de abril de 1999. Disponível em: <http://portal.anvisa.gov.br/documents/33880/2568070/res0360_23_12_2003.pdf/5d4fc71 3-9c66-4512-b3c1-afee57e7d9bc> Acesso em: 03/10/2018.

CROCETTI, A., OGLEARI, C. H., GOMES, G., SARE, I., CAMPOS, F. R., BALBI, M. E. Determinação da composição centesimal a partir de dois métodos de secagem para a produção da farinha de beterraba (Beta vulgaris, L. - Família Amaranthaceae). Curitiba, Brasil. Disponível em: <https://revistas.ufpr.br/academica/article/view/51359/31867> Acesso em: 11/11/2018.

DE ALMEIDA, M.; DE ALMEIDA, V. C. Morfologia da raiz de plantas com semestes. São Paulo, Brasil. Disponível em:<file://C:/Users/CPU/Desktop/morfologia_raiz.pdf> Acesso em: 04/10/2018.

DREHER, M. L. Food industry perspective: functional properties and food uses of dietary fiber. In: KRITCHEVSKY, D.; BONFIELD, C. (Ed.) Dietary fiber in health \& disease. Minnesota: Eagan, 1995. p. 467-474.

FORDHAM, J. R.; WELLS, C. E.; CHEN, L. H. Sprouting of seeds and nutrient composiüon of seeds and sprouts. Journal of Food Science, Chicago, v. 40, p. 552-556, 1975. 
IAL. Métodos físico-químicos para análise de alimentos. Edição 4, 1a edição digital, 2008. Disponível em: http://www.ial.sp.gov.br/resources/editorinplace/ial/2016_3_19/ analisedealimentosial_2008.pdf Acesso em: 03/10/2018.

ISMANIEL, I. A. E. M. I. Botanical Studies on Mung bean (Vigna radiata) Plants Under Some Growth Conditions. 188 f. Dissertação (Mestrado em Botânica Agrícola) - Fac. Agric. Moshtohor, Univ. Benha Branch, Zagazig, 2004. Disponível em: <http://bu.edu.eg/ portal/uploads/Agriculture/Botany/1292/publications/lbrahim\%20Abdel-Moneim\%20lbrahim Ibrahim\%20lsmaiel\%20El-Fiki_M\%20Sc.\%20Thesis.pdf> Acesso: out. 2018.

LOURES, N. T. P. Caracterização Físico-Química, Microbiológica e Sensorial de Brotos de Lentilha da Variedade Precoz. 2007. 67 f. Dissertação (Mestrado em Engenharia Agrícola) - Universidade Estadual do Oeste do Paraná, Cascavel, 2007.

LOURES, N. T. P.; NOBREGA, L. H. P.; COELHO, S. R. M. Análise físico-química, microbiológica e sensorial de brotos de química, microbiológica e sensorial de brotos de lentilha da variedade PRECOZ lentilha da variedade PRECOZ. Acta Scientiarum. Agronomy Maringá, v. 31, n. 4, p. 599-606, 2009.

MALUCELLI, M. et. al. Avaliação e composição nutricional de nhoque tradicional enriquecido com farinha de resíduo de brócolis (Brassica Oleracea Var. itálica). Alim. Nutr. Araraquara, v.20, n.4, p. 553-560, out./dez. 2009.

MARQUEZI, M., CARACTERIZAÇÃO DE BROTOS DE FEIJÃO (Phaseolus vulgaris L.) OBTIDOS APÓS DIFERENTES CONDIÇÕES DE GERMINAÇÃO E SECAGEM. 2016. Tese (Doutorado em Ciência dos Alimentos) - Centro de Ciências Agrárias, da Universidade Federal de Santa Catarina, Florianópolis. Disponível em: <https://repositorio.ufsc.br/bitstream/ handle/123456789/175845/344595.pdf?sequence=1> Acesso em: 03/10/2018.

MOURA, S. C. S. R.; BERBARI, S. A.; GERMER, S. P. M.; ALMEIDA, M. E. M.; FEFIM, D. A. Determinação da vida-de-prateleira de maçã-passa por testes acelerados. Ciênc. Tecnol. Aliment., Campinas, 27(1): 141-148, jan.-mar. 2007. Disponível em:<http://www.scielo.br/ pdf/cta/v27n1/24.pdf> Acesso em: 11/11/2018. 
OliveiRA, L. P. de; Cesconetto, G.; SCHVEITZER, B.; FOPPA, T. Avaliação e composição nutricional da farinha de beterraba e sua utilização no preparo de sobremesas. RIES. Caçador, v.2, n.1, p. 13-19, 2013.

OLIVEIRA, M. A.; CARRÃO-PANIZZI, M. C.; MANDARINO, J. M. G.; LEITE, R. S. Produção de brotos de soja utilizando a cultivar BRS 216: caracterização físico-química e teste de aceitabilidade. Braz. J. Food Technol, Campinas, v. 16, n. 1, p. 34-41, jan./mar. 2013.

PEREIRA, P. A. G. et. al. Cálcio dietético - estratégias para otimizar o consumo. Revista Brasileira de Reumatologia, v.49, n.2, p.164-171, 2009.

SANTOS, J. O. et. al. Caracterização morfológica de acessos de feijão-mungo-verde do Banco Ativo de Germoplasma da Embrapa Meio-Norte com base em descritores qualitativos. Horticultura Brasileira. Aracaju. Anais eletrônicos... Aracaju. v. 25, n. 1, ago. 2007. Disponível em: <http://www.abhorticultura.com.br/Eventosx/trabalhos/ev_1/A657_ T691_Comp.pdf> Acesso em: 03/10/2018.

SCHARDONG, E.; CALABRESI, E.; ZWICK, P.; COLOMBO, T. GONÇALVEZ, V. L. C. A resposta ao potencial de desenvolvimento do broto de alfafa (Medicago sativa L.) com o uso de luz durante o ciclo de crescimento. Revista Mirante. Osório. v. 3. n. 1. p.68-74. dez, 2013.

TACO - TABELA BRASILEIRA DE COMPOSIÇÃO DE ALIMENTOS/NEPA. 4. ed. rev. e amp. Campinas: NEPA-UNICAMP, 2011.

VIEIRA, R. F, VIEIRA, C. Leguminosas graníferas. Editora UFV. Viçosa, p. 129-140, 2001. 